\title{
ANALYSIS OF DIAMOND TITANIUM CARBIDE (WTiC) CUTTING INSERT
}

\author{
GANDHI MALLELA ${ }^{1}$, PALLAVI PATURU ${ }^{2} \&$ M. KOMALESWARAO ${ }^{3}$ \\ ${ }^{1,2}$ Assistant Professor, Department of Mechanical Engineering, Vel Tech Rangarajan Dr. Sagunthala \\ $R \& D$ Institute of Science and Technology, Chennai, Tamil Nadu, India \\ ${ }^{3} J N T U K$-University College of Engineering, Vizianagaram, India
}

\begin{abstract}
In the manufacturing process, the value is added to the materials as they undergo through the process. The fundamental manufacturing process incorporates changing the shape, physical properties and get together of the parts. The various manufacturing processes are forging, machining, welding, extrusion and casting. Machining is broadly utilized process where, the undesirable material is expelled as chips by utilizing the mechanical shear force. The basic elements of modern metal removal process are the machine, device, cutting apparatus and a control system. The persistent operation of machine instrument cause tool wear and lessening of hardware life and the outcome is poor surface complete and precision. Here in this research, we analyse tool deformation, tool life and stresses in tool by taking cutting insert for different turning operations. Force relations are calculated manually and stress deformation and other results are done by using ANSYS software which is specialized for analysis.

KEYWORDS: Cutting Insert, Turning Operations, Stress Deformation \& ANSYS
\end{abstract}

Received: Jun 27, 2018; Accepted: Jul 18, 2018; Published: Aug 06, 2018; Paper Id.: IJMPERDAUG2018102

\section{INTRODUCTION}

Single point cutting tools is generally used when performing various operations likes; turning, boring, shaping or planning. In the past, they were shaped from a solid bar of cutting tool material and were mounted directly onto the machine tool during the metal-cutting operation [1-2]. The introduction of an expensive, cutting tool material has necessitated that the body to be made of low-cost materials with a tip of cutting tool material called cutting insert.

\subsection{Various Cutting Tool Forces}

The misshaping of a work material suggests that enough force has been connected with y the device to always reshape the work material. In case a material to be reshaped, it is said to outperform its plastic purpose of constraining. A chip is a mix of reshaping and breaking. The bent chip is detached from the parent material by the break. The cutting action and the chip improvement can be more easily separated if the edge of the instrument is set inverse to the relative development of the material, refer [7] figure 1 as show below. 


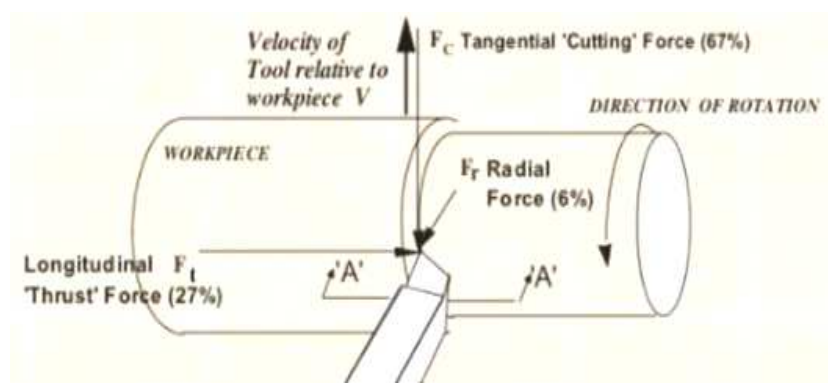

Figure 1: Different Forces Acting on the Cutting Tool

\subsection{The Diamond Titanium Carbide Insert}

The pattern in the machine configuration is towards the machines which produce the shape on the work piece. This is proficient by directing the instrument so it faces dives, turns, and structures radii, chamfers, and machines different arrangements. All together for an instrument to fulfil the necessities of these perplexing moves, it must meet certain outline gauges [2]. Since the device frequently dives along an edge, a great measure of end cutting edge angle is required. Back confronting is additionally a typical task on such setups, and this requires negative side cutting edge angle. The diamond embed was created particularly to trace the activities.

\section{MATERIALS AND METHODS}

\subsection{Preparing Geometric Model}

Cutting insert carbide, diamond tipped tool modelling is the first step for any simulation work. It essentially is the modelling of the Three-Dimensional geometry according to the necessity of the simulation. In this, the work is done in Pro/Engineer software. This particular analysis of the problem, we have to choose ANSYS software [4]. For this problem, we have collected material property is to be produced by some experimental data or engineering data sources are explored for the material properties. So for material properties, an unincorporated framework is set up for designing information by dropping building information in the independent box [5-6]. The analysis is to be done for the Titanium Carbide (WTiC) material

Table 1: Material Properties to be used for Analysis

\begin{tabular}{|c|c|c|c|}
\hline Insert Materials & $\begin{array}{c}\text { Modulus of Elasticity } \mathbf{e}^{\mathbf{5}} \\
\left(\mathbf{K g} / \mathbf{c m}^{2}\right)\end{array}$ & Density $\mathbf{g} / \mathbf{C c}$ & $\begin{array}{c}\text { Poisson } \\
\text { Ratio }\end{array}$ \\
\hline $\mathrm{WTiC}$ & 42 & 6 & 0.17 \\
\hline
\end{tabular}

In this modelling of the insert a series of operations are to be followed.

- Create the key points.

- Create the lines.

- Create the areas.

- Create the volume.

- Meshing

Building the model is the basic step involved in modelling the structure. The list of all the points through which the basic outline of the structure is obtained. 
Table 2: List of Key Points (1-8) for Creating Diamond Cutting Insert

\begin{tabular}{|c|c|c|c|}
\hline S.No & X (in M) & Y (in M) & Z (in M) \\
\hline 1 & 0.007100 & 0.000000 & 0.000000 \\
\hline 2 & -0.007100 & 0.000000 & 0.000000 \\
\hline 3 & 0.000000 & 0.003700 & 0.000000 \\
\hline 4 & 0.000000 & -0.003700 & 0.000000 \\
\hline 5 & 0.006712 & 0.000000 & -0.002000 \\
\hline 6 & -0.006712 & 0.000000 & -0.002000 \\
\hline 7 & 0.000000 & 0.003700 & -0.002000 \\
\hline 8 & 0.000000 & -0.003700 & -0.002000 \\
\hline
\end{tabular}

Meshing is the way towards separating the analysis, continuum into various discrete parts. The better the mesh, the better the outcome, however the more extended the analysis time. Subsequently, a trade-off amongst exactness and solution speed is normally made [3]. The work might be physically and via consequently.

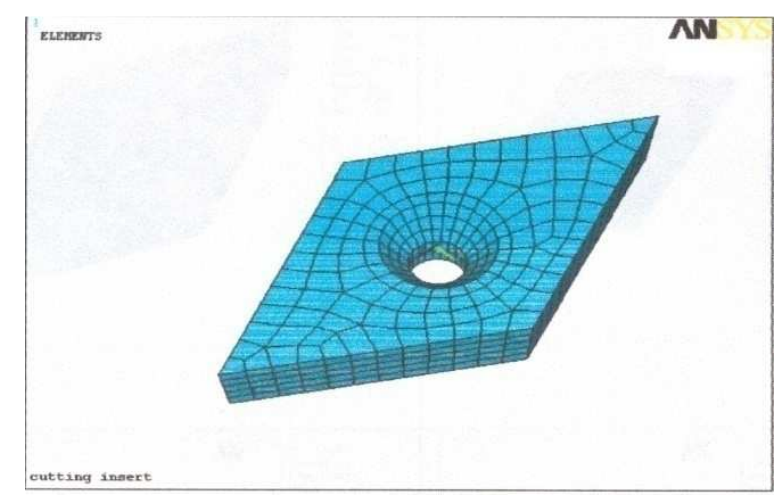

Figure 2: Mesh Generated of Cutting Insert Diamond Carbide Tipped Tool

\subsection{Analysis of Cutting Forces}

Formulae for calculating theoretical forces $\mathrm{F}_{\mathrm{z}}, \mathrm{F}_{\mathrm{y}}$ and $\mathrm{F}_{\mathrm{x}}$ in turning operations are;

$$
\begin{aligned}
& F_{x}=C_{F x} t^{x x} s^{y x} V^{n 2} k_{x} k g f \\
& F_{y}=C_{F y} t^{x y} s^{y y} V^{n 1} k_{y} k g f \\
& F_{z}=C_{F z} t^{x z} s^{y z} V^{n} k_{z} k g f
\end{aligned}
$$

Where $\mathrm{CFx}, \mathrm{CFy}$, and $\mathrm{CFz}=$ coefficient characterizing a certain metal and its machining conditions,

$\mathrm{t}=$ Cutting depth in $\mathrm{mm}, \mathrm{s}=$ Feed rate in $\mathrm{mm} / \mathrm{rev}$

$\mathrm{v}=$ Speed of cutting in $\mathrm{M} / \mathrm{min}$,

$x z, y z, x y, y y, x x$ and $y x=$ Exponents of the depth of cut and feed,

$\mathrm{n}, \mathrm{n} 1, \mathrm{n} 2=$ Exponents of the cutting speed,

$\mathrm{kz}$, $\mathrm{ky}$ and $\mathrm{kx}=$ General correction factors taking into consideration the concrete machining conditions. The table 1 list the mean values of the coefficients and exponents for calculating forces $F_{z}, F_{y}$ and $F_{x}(s<t)$ in longitudinal turning. 
The values of $\mathrm{C}_{\mathrm{Fx}}, \mathrm{C}_{\mathrm{Fy}}$, and $\mathrm{C}_{\mathrm{Fz}}$ are given for work materials of a tensile strength $\sigma_{\mathrm{t}}$ indicated in the table, in turning carbide tipped tools on which $\gamma=+10^{\circ}, \psi=45^{\circ}, \mathrm{r}=2 \mathrm{~mm}, \lambda=0^{\circ}, \psi_{1}=10^{\circ}$, operating without cutting fluid and having flank wear $\mathrm{h}_{\mathrm{f}}=1.0$ to $1.4 \mathrm{~mm}$

Table 3: Values of Coefficients and Exponents in Formulas for Calculating $F_{z}, F_{y}$ and $F_{x}$ in Longitudinal Turning with a Carbide-Tipped Tool

\begin{tabular}{|c|c|c|c|c|c|c|c|c|c|c|c|c|c|}
\hline \multirow{3}{*}{$\begin{array}{l}\text { Metal being } \\
\text { Machined }\end{array}$} & \multirow{3}{*}{$\begin{array}{c}\text { Feed } \\
\mathrm{mm} / \mathrm{rev}\end{array}$} & \multicolumn{12}{|c|}{ Coefficients and Exponents for the Formulas } \\
\hline & & \multicolumn{4}{|c|}{ Tangential force $F_{z}$} & \multicolumn{4}{|c|}{ Radial Force $\mathbf{F}_{\mathrm{y}}$} & \multicolumn{4}{|c|}{ Axial Force $\mathbf{F}_{\mathbf{x}}$} \\
\hline & & $\mathbf{C}_{\mathrm{Fz}}$ & $\mathbf{X}_{\mathbf{z}}$ & $\mathbf{Y}_{\mathbf{z}}$ & n & $\overline{C_{F y}}$ & $\overline{\mathbf{X}_{\mathbf{y}}}$ & $\mathbf{Y}_{\mathrm{y}}$ & $n_{1}$ & $\mathbf{C}_{\mathbf{F x}}$ & $\mathbf{X}_{\mathbf{x}}$ & $\mathbf{Y}_{\mathbf{x}}$ & $\mathbf{n}_{2}$ \\
\hline $\begin{array}{l}\text { Steel and steel } \\
\text { castings } \\
\sigma_{\mathrm{t}}=75 \mathrm{kgf} / \mathrm{mm}^{2}\end{array}$ & $\frac{s \leq 0.75}{s>0.75}$ & 300 & 1.0 & 0.75 & -0.15 & 243 & 0.9 & 0.6 & -0.3 & $\frac{339}{313}$ & 1.0 & $\frac{0.5}{0.2}$ & -0.4 \\
\hline
\end{tabular}

Table 4: Correction Factors $\mathbf{K}_{\mathrm{sh}}$ for Forces

\begin{tabular}{|c|c|c|c|c|}
\hline \multirow{2}{*}{$\begin{array}{c}\text { Metal being } \\
\text { Machined }\end{array}$} & \multicolumn{4}{|c|}{$\mathbf{K}_{\text {sh }}$ According to the Shape of the Cutting Edge } \\
\cline { 2 - 5 } & Plane & Convex & Concave & $\begin{array}{c}\text { Concave \& } \\
\text { Convex }\end{array}$ \\
\hline & & & & 1.05 \\
\hline
\end{tabular}

Assumptions for force calculations:

Spindle speed $(\mathrm{N})=500 \mathrm{rpm}$

Feed $(\mathrm{s})=0.2 \mathrm{~mm}$ per rev

Diameter of work piece $=80 \mathrm{~mm}$

Rake angle, $(\gamma)=10^{\circ}$

Approach angle, $(\psi)=10^{\circ}$

Nose radius, $(\mathrm{r})=2 \mathrm{~mm}$

End cutting edge angle, $(\psi 1)=10^{\circ}$

Side cutting edge angle, $(\lambda)=0^{\circ}$

Theoretical calculations for depth of cut $1 \mathrm{~mm}$ force calculations are below:

Axial or feed force, $\mathrm{F}_{\mathrm{x}} \quad=\mathrm{C}_{\mathrm{Fx}} \mathrm{t}^{\mathrm{xx}} \mathrm{s}^{\mathrm{yx}} \mathrm{V}^{\mathrm{n} 2} \mathrm{k}_{\mathrm{x}} \mathrm{kgf}$

$$
\begin{aligned}
& =399 *(1)^{\wedge} 1.0 *(0.2)^{\wedge} 0.5 *(0.125)^{\wedge}-0.4 * 0.85 \\
& =296.05 \mathrm{Kgf} \\
& =2904.25 \mathrm{~N}
\end{aligned}
$$

Radial force, $\mathrm{F}_{\mathrm{y}}$

$$
\begin{aligned}
& =\mathrm{C}_{\mathrm{Fy}} \mathrm{t}^{\mathrm{xy}} \mathrm{s}^{\mathrm{yy}} \mathrm{V}^{\mathrm{n} 1} \mathrm{k}_{\mathrm{y}} \mathrm{kgf} \\
& =243^{*}(1)^{\wedge} 0.9^{*}(0.2)^{\wedge} 0.6^{*}(0.125)^{\wedge}-0.3 * 0.85 \\
& =146.74 \mathrm{Kgf}
\end{aligned}
$$




$$
\begin{aligned}
& =1439.51 \mathrm{~N} \\
\text { Cutting force, } \mathrm{F}_{\mathrm{Z}} & =\mathrm{C}_{\mathrm{Fz}} \mathrm{t}^{\mathrm{xz}} \mathrm{s}^{\mathrm{yz}} \mathrm{V}^{\mathrm{n}} \mathrm{k}_{\mathrm{z}} \mathrm{kgf} \\
& =300 *(1)^{\wedge} 1.0^{*}(0.2)^{\wedge} 0.75^{*}(0.125)^{\wedge}-0.15 * 0.85 \\
& =104.09 \mathrm{Kgf} \\
& =1021.98 \mathrm{~N}
\end{aligned}
$$

Table 5: Various Force Calculations for Depth of Cut in mm

\begin{tabular}{|c|c|c|c|c|c|}
\hline $\begin{array}{c}\text { Depth of } \\
\text { Cut }(\mathbf{m m})\end{array}$ & $\begin{array}{c}\text { Forces } \\
(\mathbf{N})\end{array}$ & Plane & Convex & Concave & $\begin{array}{c}\text { Concave \& } \\
\text { Convex }\end{array}$ \\
\hline \multirow{3}{*}{1} & & & $\sim$ & & \\
\hline \multirow{3}{*}{2} & $\mathrm{Fx}$ & 2904.25 & 3075.11 & 3587.61 & 3416.79 \\
\cline { 2 - 6 } & $\mathrm{Fy}$ & 1439.51 & 1524.17 & 1778.31 & 1693.62 \\
\cline { 2 - 6 } & $\mathrm{Fz}$ & 1021.98 & 1082.20 & 1262.44 & 1202.33 \\
\hline \multirow{3}{*}{2} & $\mathrm{Fx}$ & 5808.55 & 6150.18 & 7175.27 & 6833.54 \\
\cline { 2 - 6 } & $\mathrm{Fy}$ & 2686.37 & 2844.30 & 3318.45 & 3160.42 \\
\cline { 2 - 6 } & $\mathrm{Fz}$ & 2043.97 & 2164.20 & 2524.89 & 2403.45 \\
\hline
\end{tabular}

\section{RESULTS AND DISCUSSIONS}

From this study, we came to know how the cutting speed and feed will influence the tool life and surface finish. We made an analysis of indexable insert which is based for different turning operations like plane, concave, concave and convex, and convex. As the depth of cut increases stresses and deformations developed in the insert are increasing. Stresses and strains induced in the insert are increasing about 50\% from plain turning to other turning operations.

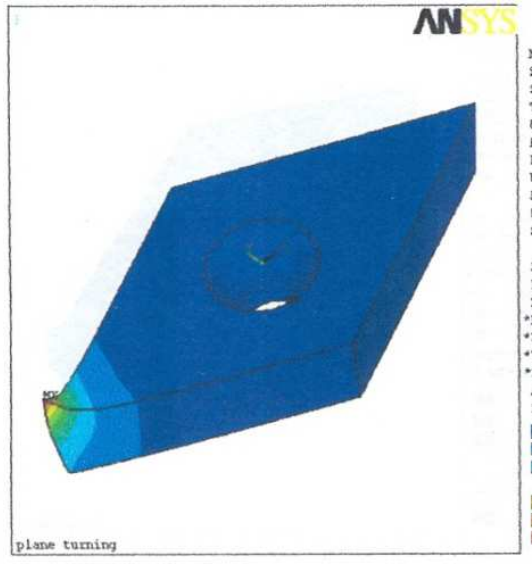

(a) Plane Turning

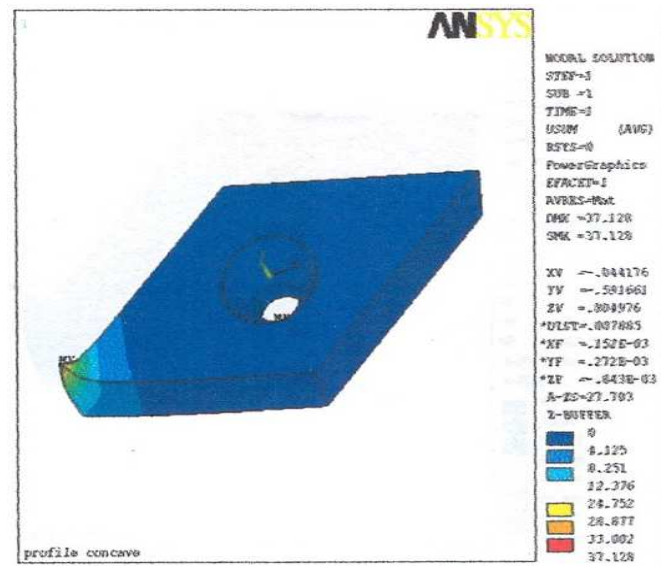

(b) Concave 


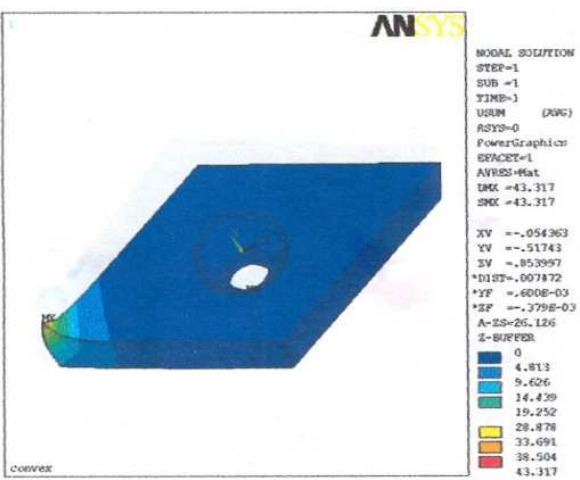

(c) Convex

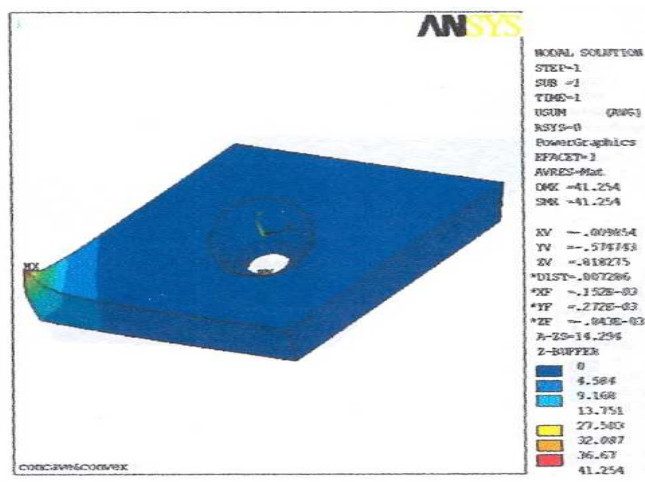

(d) Concave and Convex

Figure 3: Deformation of $1 \mathrm{~mm}$ Depth of Cut at Various Shape of the Cutting Edge

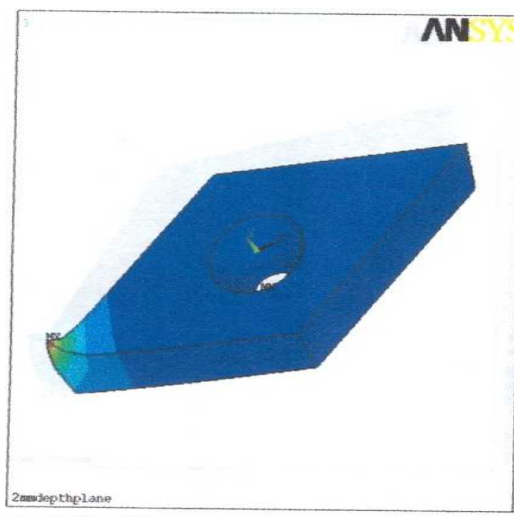

(a) Plane turning

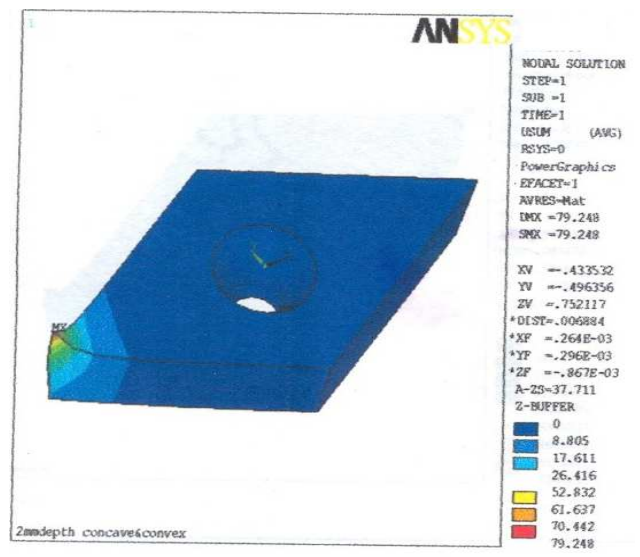

(c) Convex

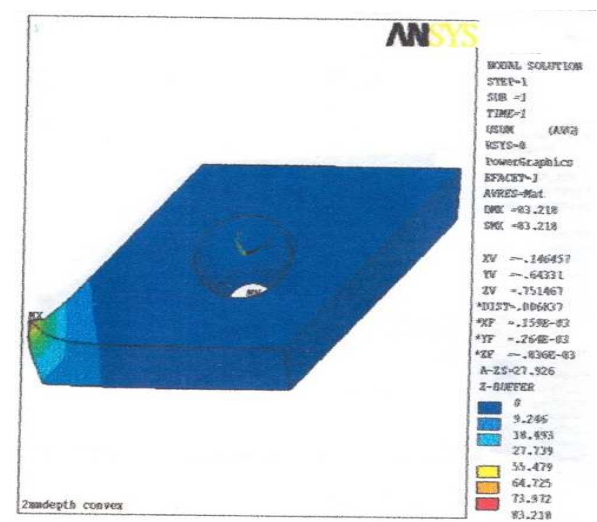

(b) Concave

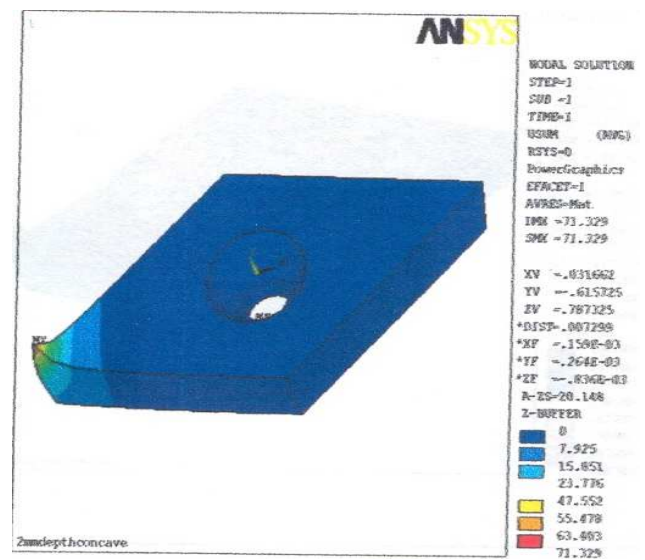

(d) Concave and convex

Figure 4: Deformation of $2 \mathrm{~mm}$ Depth of Cut at Various Shape of the Cutting Edge 


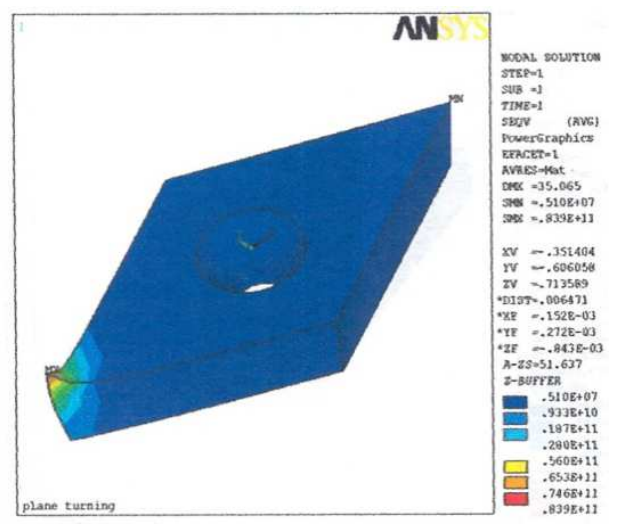

(a) Plane turning

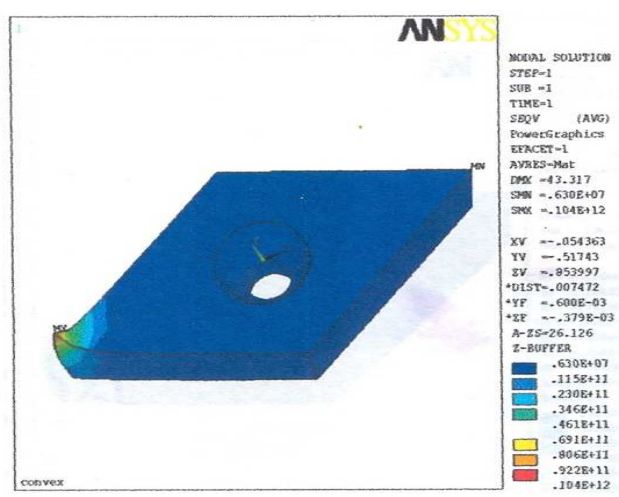

(c) Convex

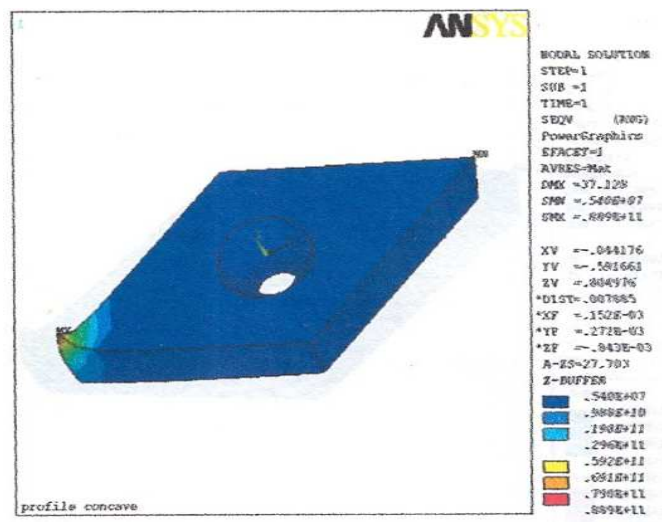

(b) Concave

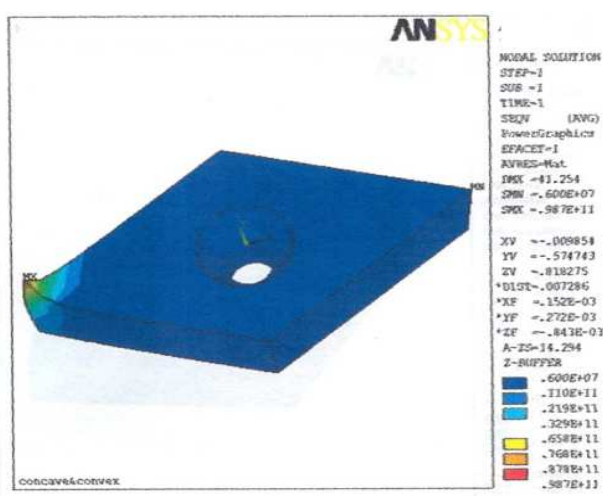

(d) Concave and convex

Figure 5: Stress of 1mm Depth of Cut at Various Shape of the Cutting Edge

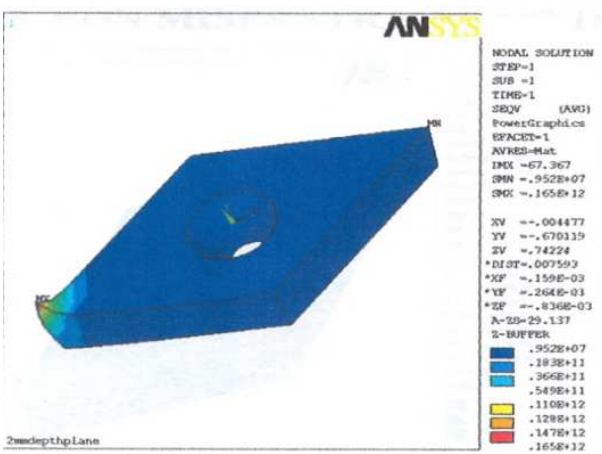

(a) Plane Turning

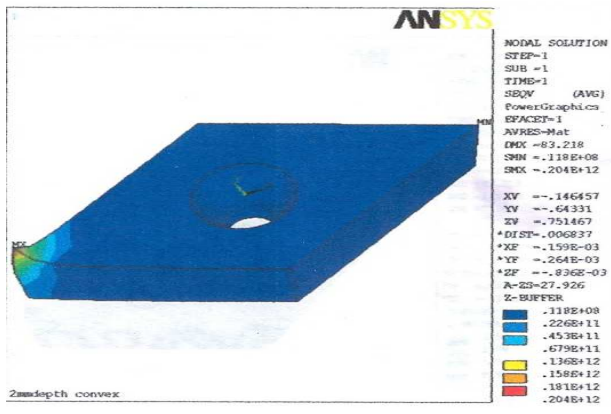

(c) Convex

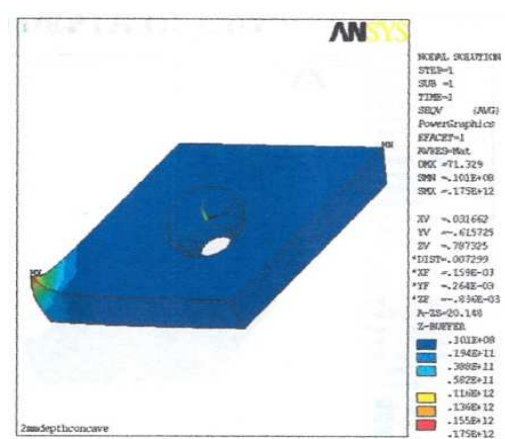

(b) Concave

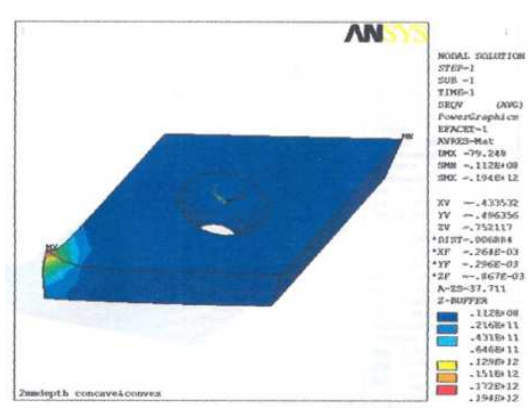

(d) Concave and Convex

Figure 6: Stress of $2 \mathrm{~mm}$ Depth of Cut at Various Shape of the Cutting Edge 


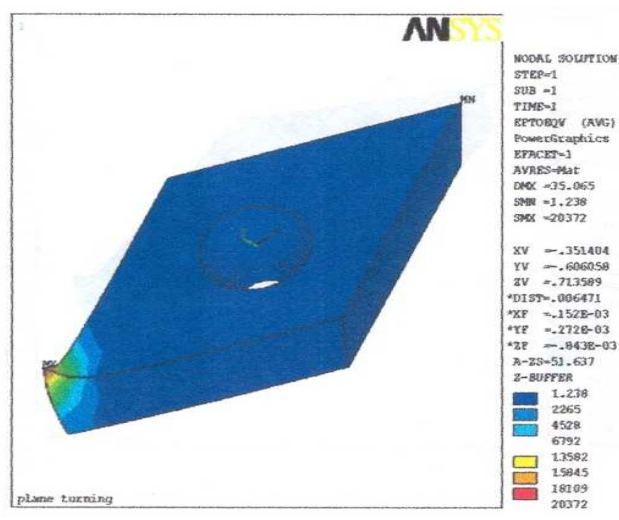

(a) Plane turning

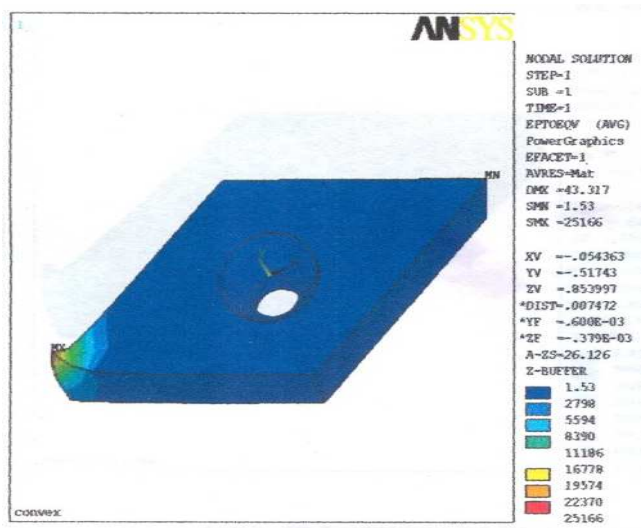

(c) Convex

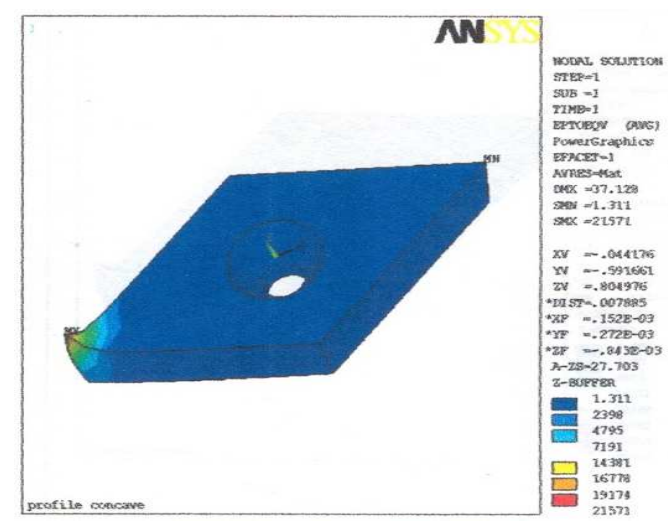

(b) Concave

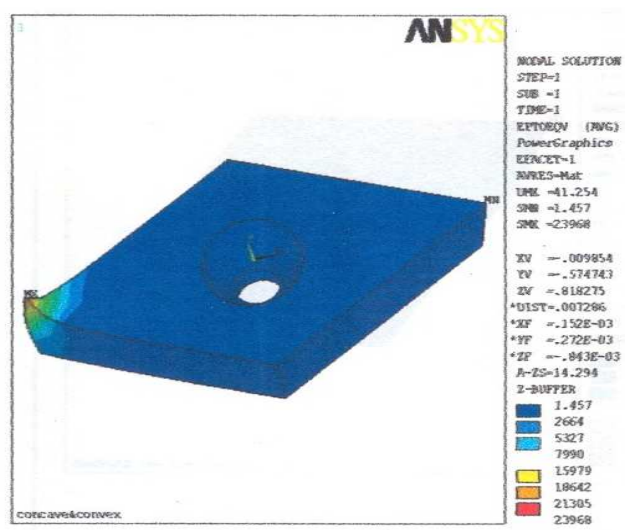

(d) Concave and Convex

Figure 7: Strain of $1 \mathrm{~mm}$ Depth of Cut at Various Shape of the Cutting Edge

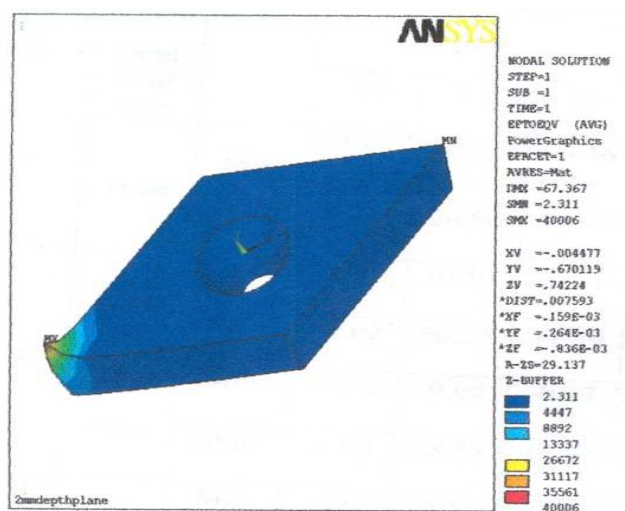

(a) Plane turning

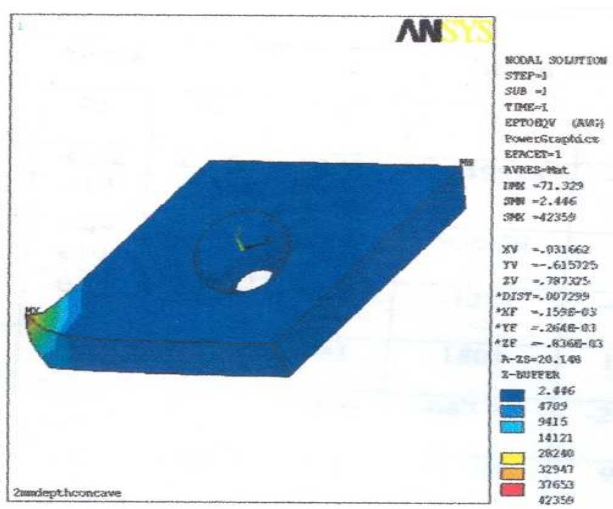

(b) Concave 


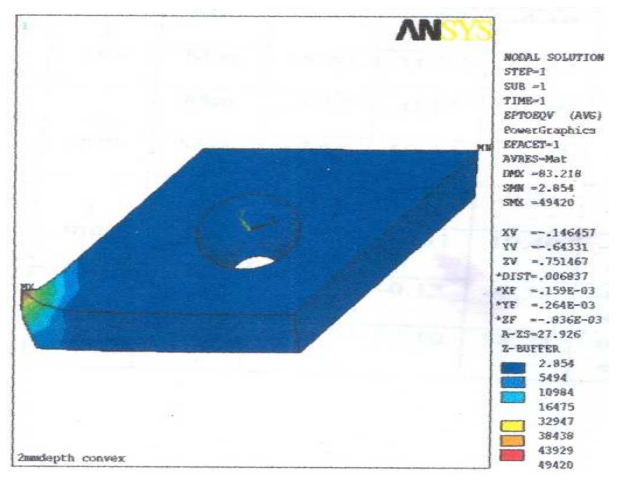

(c) Convex

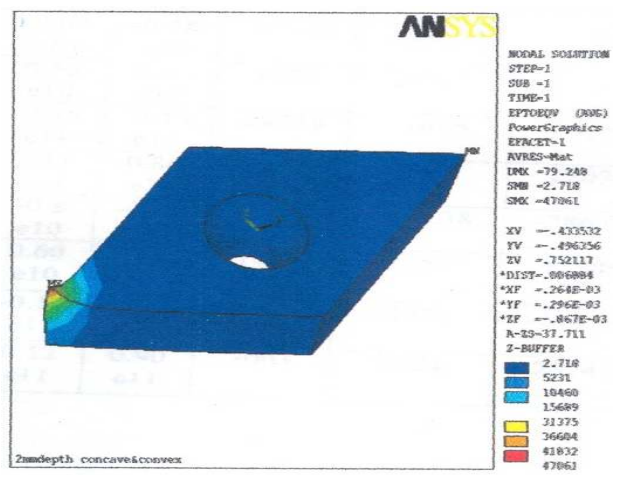

(d) Concave and Convex

Figure 8: Strain of $2 \mathbf{m m}$ depth of cut at various shape of the cutting edge

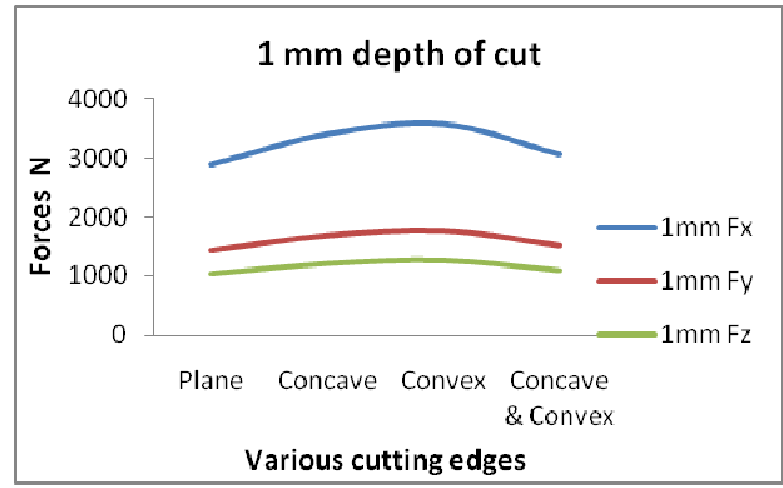

Figure 9: Force Vs Turning Operations at 1 mm Depth of Cut

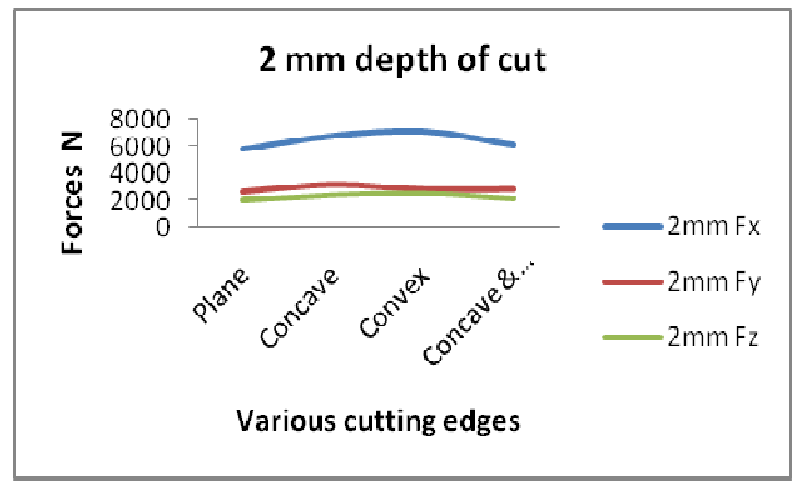

Figure 10: Force Vs Turning Operations at 2 mm Depth of Cut

\section{CONCLUSIONS}

If at all the feed and cutting speed is relatively increased there will not be much impact on the tool life and work surface finish for plain turning. But for other turning operations like concave, concave and convex, convex etc., the cutting feed plays a major role in the surface finish and tool life. If it is increased irrespectively, tool life will be destroyed. In this paper, we have done a theoretical approach and to maintain the accurate result, we have made usable software. The shape will not be much affected, if at all the inserts are worn out in plane turning, but in the case of profile turning we may lose some of the edges as well as the surface finishing. 
Tool life will be more of the inserts which are used in plane turning. The temperature distribution will be less on the insert as the contact area is less. Tool life will be less for this insert which is used in profile turning. The temperature distribution will be more of the inserts as the contact area is more. Future scope of in this paper, we have covered only static analysis as a tool will be in dynamic motion while operation there is necessity of dynamic analysis. A perfect insert material can also be selected and number of operations may be increased.

\section{REFERENCES}

1. Armarego, E Verezu, Samaranayake, 2002, The effect of coating on the cutting process friction forces and predictive cutting models in machining operations. Proceeding of the Institute of Mechanical Engineering, Part B: Journal of Engineering Manufacturing 347-356.

2. Vishal s. Suresh D. Rakesh S and Surinder kumar s (2007), Assessment and optimization of cutting parameters while turning AISI52100 steel. International journal of precision Engineering and manufacturing, Vol 9, No. 2.

3. Sainath A, Dr. Rajendra Rega, Simulation of cutting stresses and temperature on tool geometry at the onset of truing operation by FME. Paipex-Indian Journal of Research 125.

4. Ramji BR, Analysis of forces, roughness, wear and temperature in turing cast iron using Cryotreated carbide insert. International Journal of Engineering Science and Technology. Vol 2(7), 2010 and 2521 -2529.

5. Gandhi Mallela, Pallavi P, M.Komaleswararo, Lift and Drag performance of NACA0012 airofoil at various angle of attack using CFD, International journals of mechanical and production engineering research and development, Vol 8, Issue 3, 2018, 89-100.

6. James, S., \& Kumar, K. S. Machinability Analysis Of Titanium Alloys Using Digraph And Matrix Method For Common Machinable Tool Inserts.

7. Pallavi Paturu, Gandhi Mallela. S. Jebarose J, Divya S and Komaleswarao, Numerical analysis of flow over Naca0012 at fixed mach number using Computational fluid dynamics. International journal of mechanical and production engineering research and development. Vol 7, Issue 6, 2017, 213-222.

8. https://www.slideshare.net/avutu_kunduru/theory-of-metal-cutting-78791391 (figure 1.1)

9. A Harold, Stewart, Cryogenic treatment of tungsten carbide reduces tool wear when machining medium density fiberboard forest products journal, Vol. 54, No. 2, 2003. 